into reproductive age can be three times the number becoming postmenopausal. So, although women are now having fewer children than they did previously, the number of children remains high. The US Census Bureau projects no decline in the global number of births to 2050 .

The result is that the population has risen by a billion people in the past 13 years and the UN's medium variant expects about the same in the next 13 years.

None of the UN scenarios envisages a rise in fertility. If fertility stays at its present level, the UN projects 27 billion people in 2100 . Only by assuming a continuing and rapid fall in fertility do projections come down to between 6 and 16 billion.

Globally, there are 2.5 births for each death (see go.nature.com/ ows9ux). Population stability, let alone a decline, is therefore a long way off. For the foreseeable future, the world is going to be much more crowded than it is now. Robert Wyman Yale University, Connecticut, USA. robert.wyman@yale.edu

\section{Brazilian soya: the argument for}

Your scepticism about a marketbased approach to conservation in the Amazon is ill-founded (Nature 472, 5-6; 2011). It is based on a misrepresentation of the partnership in Brazil's Santarém region between US agricultural giant Cargill and environmental group The Nature Conservancy.

The aims of the Santarém partnership are explicitly environmental, not social as you claim. It was set up to reduce deforestation by enforcing Brazil's Forest Code (a federal law restricting the amount of deforestation) and the soya bean moratorium (a voluntary agreement by agribusiness not to source soya from land deforested after 2006).

The partnership monitors farmers' land-use practices in Santarém by satellite and by visits on the ground. Its contribution is crucial in the absence of a legal mechanism to enforce the soya moratorium and, given the limited government resources, the Forest Code.

Soya production in

Santarém comprises less than $0.5 \%$ of the total production of the Legal Amazon (http://sidra.ibge.gov.br), yet this small region receives intense scrutiny from scientists and the media. Despite this, no evidence has emerged that the partnership has failed to deter deforestation. We must therefore consider what the environmental outcome would have been had The Nature Conservancy not intervened. Rachael Garrett Stanford University, California, USA. rachaelg@stanford.edu

\section{Brazilian soya: the argument against}

Rachael Garrett's arguments for a market-based approach to Amazon conservation (see above: Nature doi:10.1038/474285a; 2011) hinge on the assumption that the expansion of agroindustrial development in Amazonia is inevitable. Using market mechanisms to solve environmental problems is questionable when those problems are themselves caused by market-driven expansion.

It is the relatively small soya-production area of Brazil's Santarém region that makes it an important case study. If voluntary market-based conservation programmes do not work even on a small scale, what are the chances of success for larger-scale programmes such as the Round Table on Responsible Soy (see go.nature.com/jc6ua1), hailed as the way to mitigate problems created by agro-industry?

Conservation organizations must face up to the social consequences of their programmes. The Santarém case shows that exclusively addressing environmental aspects of a complex problem exacerbates socio-political issues. The social unrest there correlates with environmental degradation in the region (C. S. Simmons et al. Ann. Assoc. Am. Geogr. 97, 567-592; 2007).

Amazonian deforestation has accelerated and extraction of its resources have continued under the market-based conservation paradigm. It is time for a radical rethink of the development model.

Brenda Baletti University of North Carolina, Chapel Hill, USA. bbaletti@email.unc.edu

\section{Peer reviews: some are already public}

Several journals are already making anonymized reviewers' reports public for published papers, as Daniel Mietchen proposes (Nature 473, 452; 2011). These include Atmospheric Chemistry and Physics (see go.nature.com/qamrfc) and The EMBO Journal (see Nature 468, 29-31; 2010). But at the European Molecular Biology Organization, we do not see an equitable way to publish referee reports on rejected manuscripts.

Instead, we favour the transfer between journals of rejected manuscripts, along with full referee reports that could be made public after acceptance of the paper. An extension of this might be to release referee names after several years, or to sign the reports with anonymized digital identifiers that could be read by official bodies to help evaluate academic performance.

Bernd Pulverer The EMBO Journal, European Molecular Biology Organization, Germany. bernd.pulverer@embo.org Competing interests declared (see go.nature.com/witfzb).

\section{Change Chinese returnee rules}

Developing countries rely on free movement of skilled scientists for the inflow of information and technology. China's rigid citizenship regulations are hindering the return of highly trained Chinese scientists from abroad, and must be changed if modernization is to be effective.

Of more than 1.62 million

Chinese who left to study abroad before 2009, less than one-third have returned. China was the second largest country of origin for science and engineering students in US higher education in 2009 (see go.nature.com/ evj2t9). Almost $90 \%$ of Chinese scientists and engineers trained overseas remained there.

At present, a Chinese researcher naturalized in another country sacrifices his or her Chinese citizenship and needs a temporary visa to return to China. Unless foreign citizenship is renounced, he or she is denied the right to open a bank account, buy a house or register a company. This bureaucracy deprives the nation of scientific and technological knowhow, entrepreneurial capital, international experience and access to professional networks.

One solution would be for China to recognize a type of dual citizenship, as in India. This would allow Chinese scientists to enjoy unlimited, visa-free trips back to China and preserve such rights as access to medical care, social security, income tax and intellectual-property protection, although not the right to vote. Jun Li International Centre for Research on Environment and Development (CIRED), France. jun.li@centre-cired.fr

\section{Worm scientist's identity revealed}

The mystery scientist so hauntingly quoted on the ubiquity of roundworms in Ralph Buschbaum's 1938 textbook Animals Without Backbones (Nature 474, 6; 2011) is biologist

Nathan Cobb (1858-1932).

Cobb's pioneering work laid the foundations for the systematic discovery and study of nematodes. Members of the Nematoda are best known for supplying us with the model organism Caenorhabditis elegans, but it is their abundance and diversity that makes them central to biology.

Cobb would have undoubtedly been thrilled, but perhaps not surprised, by the discovery of his beloved worms more than 3 kilometres inside Earth's crust. Mark J. F. Brown Royal Holloway, University of London, Surrey, UK. mark.brown@rhul.ac.uk 